\title{
Un Acercamiento a la Arquitectura del Cine
}

\section{Josefina González Cubero}

Universidad de Valladolid, España josefina.gonzalez.cubero@tap.uva.es https://orcid.org/0000-0001-8845-3503

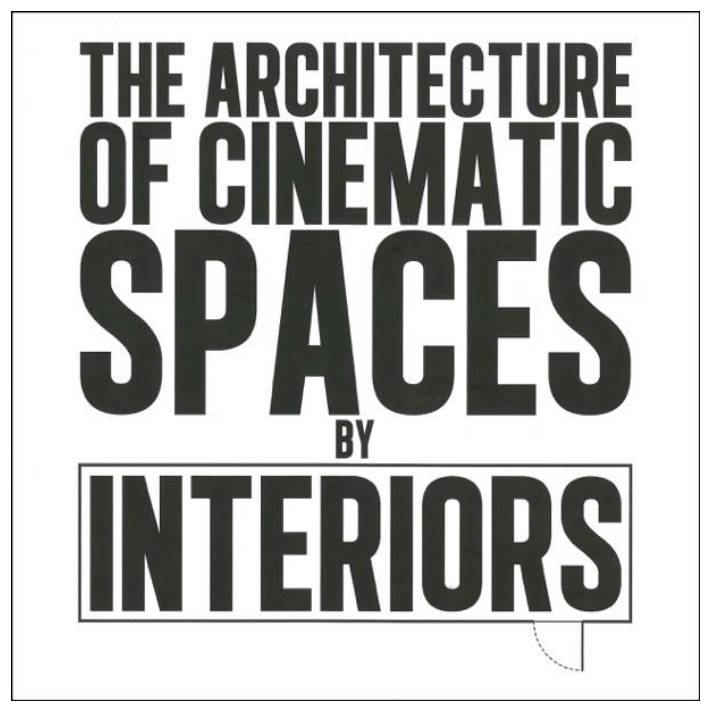

Ahi, Mehruss Jon and Ahi, Karaoghlanian, Armen. 2020. The Architecture of Cinematic Spaces by Interiors. Bristol: Intellect Books, 96 pp. ISBN 9781789382051.

Más que la búsqueda de la especificidad de cada disciplina artística, una actitud característica de siglos anteriores, en el siglo XX surgió un interés por las relaciones que establecían las distintas artes entre sí, el cual se mantiene hasta nuestros días, en este caso entre la arquitectura y el cine. Existen múltiples niveles de relación entre ambas artestécnicas, aunque en las últimas décadas ha prevalecido en más ocasiones y publicaciones la más obvia, la que estudia el espacio y la forma de la escenografía mostrada en las películas para proporcionar el entorno físico a la narrativa.

Habitualmente los arquitectos suelen realizar dibujos en el sistema diédrico (plantas, secciones y alzados) para representar los edificios 
existentes o aquellos que conciben. Son dibujos que proporcionan información sobre las dimensiones del contenido a una determinada escala métrica. Utilizando estos sistemas de representación, que sirven también a los planificadores de las escenas en el cine, diversas publicaciones han intentado desentrañar posteriormente las cualidades del espacio visto en la pantalla, es decir, ese espacio contenido en la imagen bidimensional. Con este propósito, se han restituido gráficamente escenas de películas donde la arquitectura se convirtió en un personaje más, si no en el principal. En concreto, la planta de edificios y espacios urbanos, tanto de sets de estudio como de espacios reales, ha sido un instrumento imprescindible para describir la forma de la escenografía, la ubicación del atrezzo y el itinerario de los actores en las producciones cinematográficas.

El libro The Architecture of Cinematic Spaces by Interiors, publicado por Intellect Books en 2020, también se encuadra en esta línea de relación entre arquitectura y cine. Sus autores, Mehruss Jon Ahi y Armen Karaoghlanian, son los cofundadores y editores de Interiors, una "aclamada" revista online según se especifica varias veces en la contraportada. En ella analizan, textual y gráficamente, los espacios de determinadas escenas de películas. De igual modo, en el libro cada capítulo trata sobre una película a través de un texto analítico acompañado de un dibujo en planta de la escenografía de una escena clave en la misma. Entre todas las películas abordadas por la revista han elegido diez ordenadas cronológicamente para integrar los capítulos homónimos del libro. Primero se encuentran cinco películas clásicas: The Cabinet of Dr. Caligari (1920), de Robert Wiene, Rope (1948), de Alfred Hitchcock, Le mépris (1963), de Jean-Luc Godard, Playtime (1967), de Jacques Tati y 2001: A Space Odyssey (1968), de Stanley Kubrick; a continuación les suceden otras cinco que están más próximas a nuestro tiempo: Home Alone (1990), de Chris Columbus, Panic Room (2002), de David Fincher, A Single Man (2009), de Tom Ford, Her (2013), de Spike Jonze y Columbus (2017), de Kogonada.

No está clara la pretensión del libro porque carece de una introducción o epílogo que especifique su objetivo, apenas se ha indicado en su contraportada una lacónica y ambiciosa explicación sobre su contenido: "[it] is a graphic exploration of architectural spaces in cinema that provides a new perspective on the relationship between architecture and film". Sobre su doble análisis (textual y gráfico) se especifica que es para "[bridge] the gap between film criticism and architectural 
practice”. El resultado es una mera traslación automática tanto de los textos de la revista, con alguna reescritura menor, como de su parte gráfica. El título del libro es explícito en este punto, es la revista trasladada a papel. Las películas seleccionadas no responden a una razón manifiesta que las relacione más allá de lo dicho anteriormente, sin embargo, a lo largo de las páginas se aprecia la voluntad de ofrecer un repertorio de tipos de espacios interiores diversos, la mayoría residenciales, designados con variados calificativos que los identifican: 'Expressionist residence', 'penthouse apartment', 'apartment', 'apartment building', 'extra-dimensional hotel', 'mansión', 'brownstone', 'single family residence', 'high-rise apartment', 'bank'.

Los textos de cada película son básicos, obviamente limitados por su extensión, y abordan el contexto de los directores y su filmografía, así como las escenas seleccionadas, sin gran profundidad, por lo que no descubren datos nuevos, ni proporcionan una visión crítica $o$ perspectiva novedosa como se anuncia con énfasis en la contraportada. Son sucintos resúmenes del tema, ya tratados en otras publicaciones más exhaustivas. No obstante, sirven para atraer la atención del lector hacia esta relación entre las dos artes, pero se paran en sí mismos, ni siquiera le guían hacia esas investigaciones para que sigan alimentando su interés. Así pues, se incluyen pocas referencias bibliográficas precedentes, al menos de las primeras cinco películas clásicas del cine, de las que, lógicamente, existen muchas más publicaciones en el ámbito de la historia, estética, crítica y técnica del cine. Por ello, el libro adolece de adanismo al presentar la relación entre arquitectura y cine a un lector no iniciado casi como un nuevo descubrimiento.

En cuanto a las plantas de las escenografías dibujadas por los autores, estas tienen un mismo patrón gráfico, es una representación uniforme de distintas arquitecturas que, inevitablemente, es reduccionista. Son diagramas explicativos de las viviendas con una calidad gráfica dura y elemental, derivada del empleo sin discriminación de programas informáticos de dibujo como, por ejemplo, de los bloques estándar de mobiliario. En alguna ocasión el dibujo es innecesario, pues no añade más información, es decir, cuando el espacio seleccionado es unitario y pequeño, como la residencia del Dr. Caligari.

Cuando la arquitectura real ha sido expuesta en alguna de estas películas, es una pena que el libro no sea sensible a ello y no incorpore los dibujos de sus arquitectos para localizar la escena, como por ejemplo la espléndida planta de la residencia para J. W. Schaffer (1949) 
en California de John Lautner, utilizada en A Single Man (2009), que contiene una información mucho más completa de la casa que la realizada por los autores. Tampoco la planta de la cubierta del First Financial Bank de Eero Saarinen, Alexander Girard y Dan Kiley, mostrado en Columbus, contiene una información mínimamente interesante. Es una planta carente de información gráfica por su propia naturaleza y, sorprendentemente, esta obra no es residencial y tampoco la escena elegida es interior, con lo que aparece como una incongruencia.

A pesar de lo dicho, quizá la aportación más interesante del libro sea la de reunir gráfica y texto en un somero desarrollo de información en ambos medios. Pero incluso el libro pierde categoría frente a la revista. Con respecto a la parte gráfica, porque no incluye los diagramas de movimiento de los actores en dichos espacios. Las líneas rojas describiendo las trayectorias en las plantas, que sí aparecen en la revista, aquí han desaparecido y la falta de las rojas nubes de movimientos hacen que las plantas se vean todavía más como dibujos muy grandes y vacíos. Esto parece deberse a que los autores tienen un negocio de venta de láminas sueltas con la información completa de las plantas $y$, por tanto, se la escatiman al lector del libro para que produzcan beneficios.

Con respecto a la parte fotográfica sucede algo parecido, desaparecen los fotogramas de las escenas seleccionadas, mientras que la revista los contiene. Son imágenes necesarias para hacer una lectura comparada entre las dos artes y poder contrastar la información proporcionada, pero posiblemente se deba al copyright de las películas, aunque no es suficiente excusa. Por tanto, el contenido del libro es más reducido que la revista. Ni convence la elección de los supuestos espacios significativos considerada en su conjunto, ni los textos analíticos por su reiteración, ni el tratamiento gráfico por sus carencias para estructurar el libro. De hecho, algunas de las plantas ya están publicadas en libros anteriores de otros autores.

En cuanto al diseño gráfico, la publicación en blanco y negro intenta ser innovadora. La gracia de lo pequeño desaparece para convertirse en basta caricatura. Los logotipos creados para cada película se presentan enormes a toda página, igual que las plantas de los espacios, y se destacan frases del propio texto con el mismo gigantismo, como eslóganes necesitados de su gran tamaño para convencer. El contenido derrocha superficie de papel en blanco hasta el punto de hacer que 
parezca un libro lo que es una suma de pequeños resúmenes de películas, de una a tres páginas. De sus 88 páginas la mitad son puros ejercicios gráficos destinados al impacto visual del anuncio, no tanto al intelectual de su contenido.

Los formatos de las publicaciones tienen su lugar apropiado y lo que es la virtud de la revista online se convierte en el talón de Aquiles del libro. La ligereza y brevedad del magazine de tipo blog, con entradas por cada película con una información condensada acerca de ellas, hacen de la frescura de lo inmediato y sintético un valor. ¿Por qué necesitan los autores la perpetuación de la revista en el soporte físico de libro y lo hacen sin ninguna reconsideración? Una incógnita que no se desvela en ningún momento. Es posible que para un público no iniciado pueda ser interesante, es decir, para aquellos que se acercan por primera vez a la relación entre arquitectura y cine, pero desde luego, el mejor consejo que se les puede dar es que acudan a la revista online.

En definitiva, el libro The Architecture of Cinematic Spaces by Interiors es un producto genuino de los tiempos actuales de rápido consumo. Así como las películas utilizan la arquitectura para caracterizar la atmósfera de los personajes y ponerlos en situación ante los espectadores con cierta rapidez, el libro también sigue el mismo camino. Por lo tanto, no es un estudio académico sólidamente argumentado y fundamentado, quizá ni siquiera lo pretendía. Las diez secuencias extraídas de las películas seleccionadas constituyen una breve recopilación de vínculos entre formas espaciales y diégesis fílmicas de distintos directores que, utilizando una analogía arquitectónica, son la puerta de entrada al conocimiento de esta secular y estrecha relación entre arquitectura y cine.

aniki Recensões | Reviews 